\title{
Oil, Earth, Books, and Holy Spirit
}

\section{Theological Institutions, Libraries, and the Role of Environmental Sustainability}

Anthony Elia, Bridwell Library at Perkins School of Theology, Southern Methodist University

\begin{abstract}
Theological libraries like Bridwell continue to benefit from both natural resources and the environment, while needing to adapt to the harshness of what nature itself brings. A holistic vision, distilled in the particular climates, topographies, and physical geographies of Texas, for example, reflects both the concerns and hopes about the general stewardship and sustainability of natural resources in our work. Reflecting on historical legacies will benefit our attempts to envision a better future and healthier planet. In the last few years, the focus on environmental sustainability has grown along with more critical roles in renewable energy. As theological institutions, then, it will become more pressing to evaluate both questions about what our ties are to the past, and what visions there are for the future. This paper will examine the ambiguities of environmental legacies while discussing what roles theological schools and libraries have in strategizing for coming generations.
\end{abstract}

\section{INTRODUCTION}

"The desert is a natural extension of the inner silence of the body," once wrote the French sociologist Jean Baudrillard. It is a space of perceived emptiness that is in fact a nuanced place of meaning, life, and natural expression, yet something we as humans constantly struggle to understand. The desert is also a gesture of the global landscape, a sibling of our desire for emptiness in the universe, and as Baudrillard asserts "also the silence of time." It is something that I had not considered contending with before coming to a place like Dallas or the dry earth of the southern borderlands.

When I first moved to Texas, I knew that it was going to be hot, but I didn't properly understand what that full embrace of nature would be, nor the climatic adaptability to which I would have to adjust in the extremes of those physical limits. It is after all a desert 
landscape that is varied and temperamental, desolate and beautiful, and exceedingly complex in how we human beings have come to interact with it. Over the last three years, I have become increasingly aware of these nuances of nature: of the human encounter with and adaptability to the physical space, our curious courtship with water and our manipulation of earthworks to acquire, control, and harness it, and the particular long-term issues of sustainability in such an environment. These immediate observations are tempered and articulated through yet another lens-that of natural resource legacies-and have become framed in the historical context of the state, and particularly through the roles that our predecessors on this land played. By examining and recognizing these histories and the distinctions of our different eras, we may be better tooled to assess how we got here, where we are today, and what may be the best actions going forward.

In so doing, I have come to acknowledge that we often arrive in a new place blinded by circumstances or preconceived notions. We are conditioned to think and believe ideas that precede us at our destinations and these ultimately shape our understandings, even while we begin to rethink and evaluate these circumstances based on our experiences in that new land. The present paper seeks to consider these perceptions and reconsider the temporal, spatial, and custodial relationships that we as human beings have with our planet-specifically, on this desert landscape we call Texas. This is an area-specific discussion but should not exclude us from discerning how such an example may be more widely applicable, especially as we consider the role of theological libraries and institutions within the environmental, historical, and ecological systems of our world. These points are as easily considered in the Midwest, the East Coast, the Pacific Northwest, or elsewhere. And I hope this will be the case.

My key approaches to our conversation must rely on a holistic vision of nature and the environment-terms I will detail later. And by beginning with the historical precedents to our current moment, and most specifically, the precedents that allowed for Bridwell Library to be established, survive, and thrive, I believe that this long view (Annales School social history) approach may provide us with a more articulate, responsible, and useful understanding for us to move forward. In this way, then, the holistic vision of our places of work and dwelling, and especially at our own theological institutions, will allow us to contend with not simply the historical understand- 
ings of our organic and physical surroundings, but the ethical and moral implications of those circumstances, and how we negotiate our futures. Through this approach, I hope to a) look at the terminologies of our world related to environment and ecology; b) consider our organic and holistic nature-that all things from "adam(ah)" (Heb. earth/soil/human) to books, oil, water, and more-are related in our global ecosystem, even though historically, we as humans and society have isolated and categorized the world into antagonistic models of "nature" vs. "non-nature"; c) evaluate how history itself has been based on ecological principles and environmental conditions; and d) recognize that there are three categories of assessment with which we need to engage: 1) "environmental exigencies" (physical relationships among our libraries and the environment and nature); 2) "natural resources" (including the resources which created the library-e.g. oil and livestock — and the natural resources we can use in the future); and 3) the "imperative of adaptability"-that only by thinking in these ways, can we actually succeed in the sustainability of our institutions and libraries.

My question in all of this is what is our present and future role in theological libraries, where we recognize the natural historical past, the anthropocenic adaption and encounter with the earth, and a future of studied beneficence that is sustainable and healthful for generations to come? In short, how do we best move forward in our libraries and institutions, as inheritors of a changing world that consumes more and more? (cf. Ramachandra Guha's How Much Should a Person Consume?)

\section{JESUS ON THE DINOSAUR: MEMES, PLANKTON, AND PHILANTHROPY}

I began my presentation with a cartoon of Jesus riding a dinosaur. In this playful exchange was a conversation that tried to play on both the common meme abounding on the internet-of Jesus on a variety of dinosaurs, usually with some weapon-and the paradoxical and implicit meanings that could be taken from this representation. My reason for using this was to explain both the meme and cultural phenomenon of "Jesus on Dinosaur" imagery, and the peculiar stretch of the imagination that mistakenly connects these two themes. As the cartoon describes: 
Dinosaur: I'm so glad the Creationists made us friends.

Jesus: I feel the same.

Dinosaur: But there's a little irony to it, don't you think? Little do the Mainlines know how subversive and real this metaphor is!

Jesus: You mean that after all you dinosaurs died, your organic matter decayed for millions of years, turned into oil, was sucked up from the earth, processed, sold, and through a capitalist system was used to profit by businessmen, who then used the cash to build philanthropic empires and endow theological schools and libraries dedicated to celebrating me eternally?

Of course, Jesus never rode dinosaurs. And dinosaurs don't talk. The imaginary cartoon is meant to illustrate how the assumptions about the world, the history and pre-history of the earth, the radical unity of timeless ecologies along geologic epochs, and human appropriation of natural resources tie together with beliefs and practices in the Christian religion. Indeed, I first considered using such an illustration after visiting Glen Rose, Texas, where the state's most famous dinosaur park and authentic sauropod tracks can be found, and where immediately outside of this park is a bona fide Creationist Museum. But even the cheeky long statement by Jesus to the dinosaur is not accurate: dinosaurs never became oil-the term fossil fuel was a misnomer of sorts, designated in the eighteenth century by a German chemist named Caspar Neumann (1683-1737). The connection to petroleum products and the language used to describe this became prominent after 1859 when petroleum (lit. "rock oil") was first commercially produced. So-called fossil fuels did not come then from the organic matter of fifty-million-year-old dead dinosaurs, but instead from earlier zoo- and phytoplankton remains.

The connection here then is between the Mesozoic remnants and the human practice of extracting and refining the natural resource of oil for commercial use; and specifically, the uniting factor is how one Mr. J.S. Bridwell was part of this enterprise-a man who rose to prominence in the 1920s and 1930s by drilling and gathering oil, acquiring and utilizing land and cattle, and turning significant and remarkable profit especially in the mid-twentieth century. By 1950, that relationship made another turn toward demonstrable philanthropy and the establishment and endowing of Bridwell Library, 
which would become the preeminent theological library in North Texas.

In this very long view of prehistorical and historical record, we are able to consider how the holistic vision of the earth is not simply how our worlds connect in the present, but how they connect across time. Just as the classical elements of water, earth, wind, and fire predominate the cosmologies of major societies around the world back into antiquity, so too do these elements play a role in how we understand the places we live in today. The philosopher Manuel DeLanda suggests in his classic work $A$ Thousand Years of Non-Linear History that rather than be held hostage by the historical markings of dates and places, we instead consider interplays of matter and energy when looking at the historical frameworks of the world. While this may be oversimplified, it possesses some innovative considerations around how we view history through a very different and distinct lens. Can we actually forego the recognition of dates and places? Probably not, but I think that we can evaluate the circumstances and events of history as these interplays, as instances of energy flow, giveand-take, and power shifts, such as what happened in eighteenthcentury French history; nineteenth-century British imperial history; twentieth-century American history; or twenty-first-century people's history - all as measures of matter in flux. As for our spaces of power, the environment has always been imperative, a key to the victories of battle or losses of war, the emergence of states, and the decline of monarchy. Tied into all of this and to the environmental and ecological spaces on which we tread as human creators of those histories is the very real and very fractious relationship to natural resources, the land, and the socio-political imagination-especially in Texas.

\section{TEXAS VS. OTHER PLACES: MOLDING IDEAS}

The hope that our annual conference was to take place in the DallasFort Worth area this year was much anticipated, but ultimately did not occur in-person. Part of my own desire to have this conference in the metroplex had been to coordinate how this paper would articulate the realities of visiting and being in a place suffering from drought and intense heat. It is one thing to attend an online session about environments, ecology, nature, and libraries; it's another thing to do so in person and then have to go out into the blistering sun between sessions to meet friends, go for a meal, or find your airport shuttle. 
If attendees had come in person, many would have flown in to DFW or Love Field, looking down upon an earth of empty rivulets, dry riverbeds, and a parchment-grey landscape with speckles of green in the form of hardy live oaks and craggy boscage. At the airports, you might see some vibrant artificial plantings or manicured coppices, while being choked by the thick hot air of mid-June and the encroaching summer winds, dust billows, and a brume of humidity - dry heat here is somewhat misleading. It is not Atlanta or the Gulf Coast, but there is enough humidity once you hit 100F that it makes things unpleasant. And on your drive to the conference hotel, you might pass through swanky neighborhoods, or more likely, the proliferating suburban sprawl, where there are tens of thousands of new brick façade homes, with small rectangular lots, and perfectly tended pre-made turf lawns dotted with an occasional sapling, held up by some guiding wire. Companies, colleges, and shopping centers are adorned with verdant greenswards, luscious gardens, hearty tree plantings, rustic fences, artificial streams, creative fountains, and occasional statues of mustangs or cattle drives. So much are these decorative details entrancing and distracting that we tend not to realize how much of a challenge it is for this many people to adapt to such a place, where most organic life would not likely survive, if not for advanced technologies.

I can say with confidence, now having traveled nearly to all the extremes of the state-from El Paso to Texarkana, Amarillo to Port Arthur, Big Bend to Sherman-that there is great diversity in the unity of this space, but also great similarity in its complex relationship with water. The recognition of water and our human societal designs on capturing and utilizing it for our survival is also part of our understanding of place, just as much as it is part of knowing the elements and building blocks of our workplaces, our libraries, and our institutions. This is the holistic reality.

The vision of the earth, of nature, and of the environment in Texas, and especially DFW, is a vision of a particular adaptability that is forced by a skyrocketing population, its expansive and fast-paced growth, our relationship with water, terrain, rocks, and each other, and the pressing extremes of climate-blistering heats and unpredictable freezes. I have lived all over the world, and yet in Texas, the role of nature, the environment, and climate are among the most varied and truly untamed I have ever seen. They are also much more obvious, both in the daily observations of how humankind 
has tried to carve out or control the earth here, and in the seasonal unpreparedness of our social and political administrative frameworks-such as our power grid.

While I have had these thoughts about the state over the last few years, it does not become more obvious until I leave the state, when I make observations of adaptability, construction, and harnessing of the natural environment. There are dams in New York, Pennsylvania, and North Carolina, yet they are surrounded by trees and moist earth, and there are mountains abounding with dense green cover. Water is abundant and visible, it rains more frequently, and people are cultivating more bountiful gardens. The physical environment projects different meanings to those who live in a place, as well as to those who experience and understand it from afar. Though it may not matter much to many people, the aesthetics of space do in fact have an impact on the way we live and interact with our environments (think: would you rather be at the beach, in the mountains, or in your office?). Spaces and places matter and unduly affect not just our perceptions, but also our feelings, behaviors, and ability to perform work and daily activities.

As we try to better understand our environments, those which are experienced as dramatically different from where we came from or to where we've gone will be understood, identified, and recalled in markedly different ways. Texas, therefore, stands out as a place that on the quotidian level is experienced by the human relationship between dry climate and the necessity of water for our sustenancenot a quality you would generally think about or consider in New York, Pennsylvania, or North Carolina. Environmentally, though, the second distinction of Texas is of its natural resources-its natural gas and oil reserves. Though water is certainly more precious and necessary for human life, oil and gas are highly useful-some would say not just useful, but necessary - for our ability to operate the world as it is currently set up: reliant on fossil fuels. Thus, the relationship we hold with the land is one of a communal relationship with the environment through the specific needs of natural resources, like water, gas, and oil.

Yet, our recognition of these two key resources is just the beginning, because even if we estimate this as part of the makeup of our worlds, we must take that additional step, recognizing that we are living now and forever in an organic and holistic environment that encapsulates us within a geochemical and geothermal space. Even 
in the antique pronouncements of from dust we came and to dust we shall return, the notion of our physio-chemical relationship to the earth must be acknowledged in how we understand not just the resources that founded our libraries, but also those resources that created all the elements that comprise the very library buildings themselves - the clay for the bricks, the mortar, the wood and metal frames, the ancient rock materials of slate or composite stone that cover the roof, and the piping that ushers around clear liquids, oils, and sludge. Just as important, and certainly even of more interest to our staff and patrons, are the books themselves-bought with and supported by the monies and endowments founded in oil and cattle profits, and created from sheep skins, vellum, and paper, made from pulp, from ground tree scraps, mixed together and glued into something viable. Those trees came from the earth somewhere, gaining nutrients from variegated soils that were torn up, ground, and circulated over millions of years, themselves settled above in a violent atmosphere that covered hundreds of feet of ground and earth, protecting those ancient phytoplankton deposits, now oil and gas.

Every place on earth is different-the genetics of the earth, the soil, the humus of antiquity that was made by the Big Bang or the gods or the Eternal Creator are all unique. That is the long history of the environment and humankind. How we reconcile our distinctions and categories with this fluid mixing of the untamed universe is the challenge, but also the reality of knowing that we are all part of the same physical, psychological, and spiritual ecosystem.

\section{TERMS TO CONTEND WITH}

There is a mighty lexicon when discussing the environment. Terms like ecology, deep ecology, environmental history, ecosystem, and environmentalism among others have long histories and meanings associated with them, and at times are misunderstood by the general public. Before diving deeper into the terrain of this paper though, it will be useful to provide the very basic definitions for how to deal with these issues and concerns. Thus, it will help guide us and shepherd a sincere consideration of what those of the last century worked on and believed in contrasted with those of today, who often and easily mark the past with criticism and lament. Additionally, this will help us recognize the paradoxical nature of persons living in the last century with how they viewed their work and how we view ours 
in their long legacies for us today. The contemporary moralization that often comes with discussing fossil fuels, for example, and specifically petroleum, problematizes the history of those who benefited from oil at some point in history, as well as those who contend with and benefit from it today. This is neither to condemn nor to praise oil consumption, but to recognize the complex nature of long-view histories, the roles of people in those histories, and how we may best articulate those circumstances and move forward into the future.

Ecology is the study of relations of organisms in their surroundings; Environmental History is the study of how the natural world and humans interact with and affect each other; Environmentalism is action-based practices and movements of protecting the environment; Deep Ecology is the belief that places human life in equivalence with all other parts of our global ecosystem; Ecosystems are communities of interacting organisms and their environments; Environmental Justice is the fair treatment of all peoples with respect to design, implementation, and enforcement of environmental laws; and Environmental Racism is where these laws ignore or harm groups based on race. While each of these terms is unique, they are also very much connected in their indebtedness to how we as human beings exist and operate within our world. Each expression presses us to distinct moments or frequencies of behavior, action, and reaction, such that our best option in understanding these relationships is to recognize their interconnectivity, and the power of communities.

Now that we have these terms in front of us, how do they fit into this discussion about the considerations of fossil fuels, about the legacy of those natural resources, and what we might do with the present consideration? To do this, we will begin with Mr. J.S. Bridwell himself and the complex view of how we understand and evaluate history from afar.

\section{JOSEPH STERLING BRIDWELL: OILMAN, SOIL INNOVATOR, ENVIRONMENTALIST?}

The first description of Joseph Sterling Bridwell, if one were asked to describe him, would be oilman, cattleman, and philanthropist, but very unlikely environmentalist. Yet, within the conundrum that we face today, a common assumption that those employed or engaged in the fossil fuel industry are inherently against environmental conservation, action, and preservation is not completely true; nor was it 
true before the bruhahas of the late 1970s and 1980s, when the global warming and climate change debates became simultaneously overtly and covertly political. Mr. Bridwell would certainly not recognize such dualities today, nor the mutually exclusive arguments that you must be against environmental conservation if you deal in oil.

For his sake, Mr. Bridwell was a remarkable practitioner of both the old-fashioned arts of business and the entrenched nature of regional politics: land acquisition, mineral rights, cattle raising, and oil drilling. He was also very much concerned with soil conservation and started a contest among farmers and ranchers related to cultivation. He believed that cigarette smoking was bad for a person's health and the environment and even instituted an annual smoking cessation program for his employees, which garnered a \$50 bonus in the early 1950s for those who quit for a year. He also was very much concerned with child and human welfare, setting up an orphanage in Waco. And of course, he established and endowed the Bridwell Library. Though his actions describe the work of an environmentalist-though perhaps not of the ilk of a Muir or BurrowsMr. Bridwell maintained a steady vision and ideology that you need to tend to your land, in order for it to be beneficial to your crops, to your animals, to your families, and to yourself.

\section{NATURE AND ENVIRONMENT IN CONTEXT}

'As soon as we label something as 'natural,' we attach to it the powerful implication that any change from its current state would degrade and damage the way it is 'supposed' to be." -William Cronon, Uncommon Ground: Rethinking the Human Place in Nature

The dry and unforgiving climate of North Texas was both a challenge and opportunity to the early non-Indigenous residents of the region. Those who came to settle on farms and tracts of land in the early twentieth century found space to do work with land and livestock, but also oil-the key ingredient to the successes of many Texas business folk. A century later, we are talking about the so-called Californization (or Californication) of the state, which can be defined in any number of ways, but primarily as the influx of California residents, with an assumption that with those transplants will also come their values, taxes, laws, and regulations-which predominate on the left (sometimes it is even seen as a form of cultural imperialism). I would add to this a somewhat different definition, which would 
include some expression of Texas becoming more like California in its long battles over water rights and use, adaptability to natural environments and how we as human actors on earth are being better stewards of the land we tread, but also fulfilling the consumerist tendency to overbuild and overpopulate spaces that might not necessarily be able to handle the expansive growth of a place that is not intended for such densities of human settlement.

This brings us to the very terms "nature" and "environment" themselves. Nature, curiously enough, comes from the same word in Latin for "born" or "birth," which is to say that the earth, the world, and the planet were at some point "born" out of the universe. Therefore, nature is that closest contact with the origins of life. (Interestingly, nation comes from the same root related to birth, and has a similar organic quality of the nation arising from the elemental soils of the earth). Nature is generally defined as "the collective phenomena of the physical world, including plants, animals, the landscape, and other features of the earth, as opposed to humans and human creations;" this definition is a version from one of the Oxford dictionaries. But this may be where part of the problem for us lies, because if we consider the thoughts and words of the historian William Cronon, whose quote I have shared at the start of this section, nature should not be differentiated from the human. Cronon's contribution to the contemporary philosophy of nature is that in the modern world, nature has come to be split apart from the human world, likely since the Industrial Revolution, and only in our renewed thinking, can we readjust to assume and recognize that nature includes people, cities, industry, and the ingenuity of the human mind. Perhaps it is that "nature" has become so enmeshed with the ideas of pristineness or wilderness as counterpoints to or distinctions from that which has been "touched" by people, that it's almost irretrievable to think otherwise. The need to reclaim this older vision of a holistic universe, the one which Cronon posits for us, is a true reclamation of nature as "the entirety of our world."

The term environment is often described as "the surrounding or conditions in which a person, animal, or plant lives and operates." Another definition, similar yet distinct, is "the natural world, as a whole or in a particular geographical area, especially as affected by human activity." These both possess points of origin and contact: the origin of the organism, whether human or animal or plant; and then some recognition of a relationship in a surrounding. The term 
has been around for centuries, coming originally from an Old French word meaning "to encircle." But in the contemporary sense of ecological and environmental relationships, it is generally understood to have been first used by a German scholar and founder of biosemiotics ("how people perceive themselves and symbols in the world around them”) named Jacob UexKüll (1864-1944). Understanding these terms and their contexts is integral to recognizing the spatial, physical, and mental projections we have around the very terms in question, and the way that we process information and interact with these very surroundings. We must consider the particularities of this holistic universe, down to the elemental structures that make up the planet and how they fit into the diversification of both ideas and objects. And for us, these ideas and objects make up our libraries, theological schools, and greater institutions.

\section{ENVIRONMENTS AND NATURAL RESOURCES}

Now that we have determined that nature and environment have both specific and somewhat ambiguous parameters, let us turn to the nuances around how these have played out in a place like Bridwell Library, as well as how we may better understand the construction of the library and its contents in relation to that holistic model.

The physical library is essential. As I noted, we often say that "the library is the people," but I would almost certainly be sure that not a single colleague in our workspaces would say "okay, sure, I'll go out and work on the grass! I don't need an office.” Of course not. While it may be true that our workers, staff, and employees generally speaking are what constitutes our labor force and communities, we have to work somewhere. Our buildings are all distinct, unique, and regularly in need of repair. All buildings need attention and maintenance. In order to best understand our libraries and collections, we need then to start with the buildings, and how the composite makeup of these places impact the institutions themselves.

What kind of building is it? New or old? Is it adaptable? Should it be torn down, replaced, rebuilt? Who owns the building? Is it standalone or part of another complex system? What are the deferred maintenance issues? Who is aware of them? Who is not? How does this affect people in the building? And how do the problems of the building - its air-handling and HVAC issues; its leaks and plumbing concerns; its structural inadequacies and outdated internet, Wi-Fi, 
and wiring - affect the people in those buildings? What about how environments in library spaces affect patrons negatively or positively? Or elements of nature like floods, heat, or cold affect the materials in a collection, the IT infrastructure, or the building itself? I write these things at the very same time the world is fixated on a Florida high rise that collapsed last month due to the very issues of deferred maintenance, toxic management, and poor communication. Who says that cannot happen in our workplaces?

On the other side of the environment question is the consideration of natural resources. Yes, we look at environment in terms of how nature both sustains and deteriorates our spaces, but there is also the fundamental requirement to analyze what can be brought forward to prevent and correct those deteriorations, to give more life and guidance to those undergirding assets that are meant to preserve and empower our institutions. This means recognizing the historical precedents and legacies of fossil fuels, while also looking toward renewable energy, in water, wind, geothermal, and nuclear power. How do our institutions score when looking at their track records of more environmentally friendly investments? Is this transparent or hidden; and should institutions invest more in these kinds of projects? Can libraries be not just "more green" but seek to have more integrative spaces that capture $\mathrm{CO}_{2}$ and generate oxygen? Can they recycle materials to create furniture or art rather than having thousands of plastic bottles, building byproduct, or old tech equipment go back into landfills, or worse, the oceans? Can there be better ways to capture $\mathrm{CO}_{2}$ and eliminate other aspects of the carbon-producing cycle? These are not new questions, but they are questions for us to consider in our own circumstances.

\section{TOWARD ADAPTABILITY}

In this grand scheme of a singular universe that is made up of multiplicity and diversity, there are many ways to evaluate the process of nature and environment, and specifically of natural resources. But even with these options, perhaps the most important step in this process is adaptability. For even if you have all the necessary components that will allow you to undertake a viable plan around recognizing and implementing issues of environment and natural resources, your project shall only be average. The key ingredient to exceptional success and a move toward better accountability and 
implementation will actually be adaptability. Adaptability is "the quality of being able to adjust to new conditions," or "the capacity to be modified for a new use or purpose." The point here is that we must be more and more flexible-though, not to the point where our flexibility inhibits us and makes us lackluster and without any concentrated focus.

Bridwell, for example, has been gradually moving toward a place of adaptability-through technological changes and roles in how we approach the processes and management of the library. During a recent renovation, we had various meetings dealing with lighting, and saw many lightbulbs transition to LED; furniture, rugs, and equipment have been procured from vendors and factories that make their materials from recycled plastics and fibers; motionsensor lighting, fountains, and paper towel dispensers are now the norm; and biochemical testing on ancient objects to determine dating has also found a place in our library. And though we have not yet implemented it, there have been discussions about dehumidification systems and recycling of water; other forms of recycling local plastics for artistic and corporate use; and the most innovative idea of them all-the development of a soy-based ink for traditional printing presses, in order to eliminate toxic fumes from off-gassing print runs.

We must adapt, or else we will not be able to succeed, in the sense that we will not be able to survive in such a harsh environment. Adaptability is a word laden with compromise and negotiation, though it is required in order for us to find a place in the grander scheme of our daily work, exercise routines, and meal planning. The environment and nature are less likely to yield to our demands than we are to theirs. But this is fundamental to how we envision things-our spaces, our environments, nature, and even the idea of landscapes. I spoke about the long view of history at the start of this paper, and how that provides a different framework for our themes today. I recently noted in an essay how SMU likely didn't have cars or a parking lot in 1920-five years after Ford built a plant here. But I was wrong and discovered from our university archivist Joan Gosnell not just that SMU had cars and a parking lot in 1920, but that there were scores of cars here in 1920 (she even showed me a century-old photograph of this!) -far more than I had imagined. Additionally, those cars parked all across the gravelly roads in front of Dallas Hall. 
The point of this is about our adaptability. It is about our penchants and behaviors that demand our points of view change, even slightly, in order for something to grow and develop for the better. In the case of our 1920 example with those cars and parking lots in front of Dallas Hall, it was about early twentieth-century adaptability. For us today, that adaptability is far more complex, not fully articulated, and something that will easily succumb to alternating and conflicting narratives. Yet it is still there and requires us to look closely at things that are new and burgeoning, like technology, smart buildings, and automated landscapes where underneath the magnificent greenspaces run cables, wires, and another universe of twenty-first-century connectivity.

Our adaptability in recognizing space, nature, and environment is all part of this vision and proposal. We must adapt to be better stewards and caretakers of our planet, and this will likely only happen if we have this mental construction that the entire world is connected and part of something intertwined and pulsing, alive. In this way too, we will need to consider the world, but begin with what we see before us: the local-because that is easiest to recognize, respond to, and engage with.

\section{EMPIRES OF GRASS AND GREEN}

In this greater holism, of which I have spoken, there is one final consideration in the adaptability, that is both a recognition and a caveat. In these many acts of adaptability, we find that our human actions can make us live, work, survive, and thrive in such ways that are beneficial to our own sustainability. But what about the cases where we push those limits of adaptability into the absurd? By this I mean the circumstances where a tree dies and because that tree was so large, aesthetically beautiful, and incredibly expensive, it must be replaced. Stories like this abound at SMU-there are no official histories, save a few anecdotal pronouncementsabout how the adaptability of nature has been so incredibly intense, even aggressive, that the acts of adaptability themselves became incredible. The most famous, of course, have been the replanting of the massive live oak some years ago, at a cost of six figures; or the dead tree near a wedding venue on campus that needed to be spray painted with green paint so as not to "ruin the landscape" views for the nuptial photographs. I didn't believe this story until one of my 
staff presented me with a keychain that had one of the offending leaves, replete with green spray paint on it, set inside some sort of clear acrylic.

The absurd comes in many shapes and sizes. The notions of the manicured lawn play into ideas about landscapes-ideas themselves which have changed since the eighteenth century and the provisions around what a space means. Spaces that were again "untamed by humankind" were willed into existence as wildernesses or pristine nature. With the rise of empires, nations, and the formalized structures of the state came the development of new ideas about landscapes, especially as they were tied to gardens. Official, state, or government sponsored botanical gardens were objects of the social and political gaze. They are articulations of space and place, which are delineated by a crafted vision of landscape architects, stone craftsmen, water engineers, and a host of other specialists. Their structures of demarcation lay down lines similar to boundaries and borders of modern countries-this is our land, that is yours! Within those boundaries we imagine particular patterns of space, movement, and behavior that are distinct from their surroundings-within the university they act one way; without the university they act another. The roads that line the university campus are lined with austere buildings of Georgian or Edwardian brick, and driveways lead in particular fashion either to facilitate or hamper traffic patterns. Walkways lead near waterworks and displays of perennials and annuals. The structure of the university is one of order, compliance, distinction, even while it is meant to foster and facilitate free thinking, just as the structure of the state (and particularly a democracy) is to set order, compliance, and distinction, while allowing its citizens some level of "freedom." But that is not always the case, of course.

This is not all to say that the construction of gardens in the late Renaissance, Early Modern, or Enlightenment eras of Europe all have their natural evolution in the structures of American liberal arts colleges, but there is something vital and true in this assertion. It is more important that we acknowledge that our world is still very holistic, organic, and connected, but that all the trappings of power, where the rise of financial instruments and wealth, the emergence and evolution of the state, and all those institutions that are extensions of or belonging to the nation as a total unit have come to create, delimit, and establish lines of hermeneutical space: 
landscapes, courtyards, gardens, boulevards, lawns, planted trees, and the architectural renditions of the human mind. Yes, the divisions of space are implemented by the very definition of "architect," from the Greek "chief" and "builder, fabricator." That job has been handed down from the gods to the king, from the king to the nation and state, and now to the people. Divisions and artificial categories will always exist, but perhaps now is the time that a democratized vision of the world, including our theological libraries and institutions, will finally acknowledge the nuances our entire world-nature and environment - that are both organic and comprehensive. 